\title{
Clinical Evaluation of Patients Who Underwent Pleuracan Drainage due to Pleural Effusion in the Emergency Department: Review of 54 Cases
}

\author{
Nazmiye Koyuncu, (1) Abdullah İbrahim
}

Department of Emergency Medicine, Health Sciences University Haydarpasa Numune Training and Research Hospital, Istanbul, Turkey

\begin{abstract}
Introduction: This retrospective study aimed to investigate the clinical status of 54 patients with massive pleural effusion who had Pleuracan drainage in the emergency medicine department, and to evaluate the compliance with the literature. Methods: The medical records of 54 patients who underwent drainage using Pleuracan due to massive pleural effusion in the emergency department between January 1 and December 31, 2016 were obtained. They contained data concerning their demographic features, the cause of pleural effusion, the patient's complaints, the characteristics of the pleural fluid, and complications during the procedure.

Results: There were 54 patients who underwent drainage using Pleuracan in the emergency department in 2016. Of these patients, 51\% were female, and 48\% were male. The mean age was 70.62 (36-88) years, and 50\% of the patients had history of pleural effusion. The most common causes of pleural effusion were cardiac failure (48\%) and malignancy (37\%). The main complaint was dyspnea (81\%). Pneumothorax occurred in four patients (7\%) after drainage using Pleuracan. No other complication was observed during the follow-up. The pleural fluid had exudative characteristics in 10 cases and transudative characteristic in 44 cases. Of the patients, 1 (1.8\%) died during follow-up, while 3 (5.5\%) were discharged, 5 (9.2\%) were transferred to other hospitals, and 45 (83\%) were hospitalized.

Discussion and Conclusion: In the evaluation of 54 case series of drainage using Pleuracan due to pleural effusions in one-year period, we obtained results consistent with the literature in terms of diagnosis, etiologic causes, treatment, and complications.
\end{abstract}

Keywords: Dyspnea; emergency department; pleural effusion; pleuracan; pneumothorax.

$P^{\prime}$ leural effusion is the most frequently encountered pathology of the pleura, which can be seen in many diseases rather than in one single disease caused by pathologies that disrupt any point of formation and absorption mechanisms of pleural fluid ${ }^{[1-4]}$.

No clear figures exist for the incidence and etiology of pleural effusion in Turkey. However, it has been reported in the US that pleural effusion developed in 1.4 million people, and the most common causes were congestive heart failure, pneumonia, and cancer, followed by pulmonary embolism, viral diseases, coronary bypass surgery, cirrhosis, intraabdominal diseases, and uremia ${ }^{[5-7]}$. Metastatic pleural tumors, especially involving lung and breast, are common causes of effusion. Metastases affect more than

Correspondence (Illetişim): Nazmiye Koyuncu, M.D. Saglik Bilimleri Universitesi Haydarpasa Numune Egitim ve Arastirma Hastanesi, Acil Tip, Istanbul, Turkey

Phone (Telefon): +90 5333916165 E-mail (E-posta): koyuncunazmiye@yahoo.com

Submitted Date (Başvuru Tarihi): 03.11.2018 Accepted Date (Kabul Tarihi): 06.01.2019

Copyright 2019 Haydarpaşa Numune Medical Journal

This is an open access article under the CC BY-NC license (http://creativecommons.org/licenses/by-nc/4.0/). 
200.000 people annually in the US, and they are the most common causes of exudative pleural effusions following infections ${ }^{[5-8]}$.

Pleural effusion is a frequently encountered condition in emergency services. Respiratory distress, chest pain, and dry cough are the most common symptoms. These patients are usually tachypneic, tachycardic, and dyspneic. Respiratory sounds are reduced in the area of effusion, and dullness is detected in the percussion area ${ }^{[9-12]}$. The first step in the diagnosis of pleural effusion is posteroanterior chest radiography. For the diagnostic approach, computed tomography is the first imaging diagnostic tool to be resorted to. Ultrasonography is important in the diagnosis of loculated fluids ${ }^{[9-12]}$.

Effusions impairing respiratory function require immediate intervention. For this purpose, thoracentesis, tube thoracostomy, and other thoracic catheters are applied. Thoracentesis is a procedure that provides fluid and air drainage from the pleural space with a needle, and it can be applied for diagnosis and treatment. Tube thoracostomy is the process of placing drain in the pleural space ${ }^{[12,13]}$. Large-diameter thoracic catheters and small-diameter thoracic catheters (SDTCs) can be used to drain the pleural space. In the literature, catheters smaller than 20F are usually referred to as SCTC . SDTCs generally cited in the literature include Pigtail (7-8.5F, Cook Critical Care; Cook Incorporated; Bloomington, IN), Plöroken (8-10F, B. Braun, Melsungen, Germany), and Pleurx (15.5F, Care-Fusion, San Diego, CA, USA). They are marketed in different brands and diameters ${ }^{[14]}$.

The Pleuracan catheter (Pleuracan, B. Braun, Melsungen, Germany) is a radiopaque catheter made of polyurethane with diameters of $8-10 \mathrm{~F}$ and measuring $2.7 \times 450 \mathrm{~mm}$. It is usually used for the drainage of benign pleural fluids or fluids in loculations. There is a protective sheath around the catheter. The outer cannula is $3.35-78 \mathrm{~mm}$ in diameter. It is made of two-way stopcock, double-valve spacer, drain bag, and 60$\mathrm{mm}$ injector parts. The tip is located in a sharp tubular guide apparatus (cannula). Thanks to the outer pouch sheath that encloses the entire catheter, the introduction of air from outside of the chest cavity during the procedure, and thus development of iatrogenic pneumothorax, is prevented.

The most frequent complication of thoracostomy is pneumothorax (5\%). Other complications may include pulmonary contusion, liver rupture, splenic rupture, hemothorax, local hematoma, intraabdominal hemorrhage, and air embolism $[12,15,16]$. When thoracentesis is performed, no more than 1000-1500 ml of fluid should be discharged at a time. If large amounts of fluid are evacuated within a short time, pulmonary edema and severe hypotension develop in some patients ${ }^{[15]}$.

The first thing to do after taking the pleural effusion sample is differentiation between transudate and exudate. Effusions with transudative characteristics are caused by oncotic and hydrostatic pressure changes in the pleura. Endothelial and pleural integrity was preserved. If these pressure changes are corrected, the pleural fluid spontaneously disappears. The most common causes of transudative pleural effusions are congestive heart failure, cirrhosis, and pulmonary embolism. Exudative pleural effusions develop due to the change of local factors in the pleura. The most common causes of exudates are pneumonia, cancer, and pulmonary embolism.

In this study, we evaluated the age, sex, and demographic characteristics of the patients with massive pleural effusion in whom pleural fluid was evacuated for the treatment by using Pleuracan in the emergency medicine clinic in our hospital. This study aimed to perform a case series analysis and review the compliance of the data with those of the literature.

\section{Materials and Methods}

This study was carried out between January 1 and December 31, 2016, to determine the patients who were diagnosed in SBUHNEAH Emergency Medicine Clinic as having massive pleural effusions that were decided to be evacuated with the intention of treatment using a small-caliber 8-10F thoracic catheter Pleuracan (B. Braun, Melsungen, Germany) The records of these patients were obtained from the ICD 10 diagnostic coding system. During this period, Pleuracan catheter was inserted in 255 patients in the hospital, and 54 of them were implanted in the emergency medicine department. Data related to age, sex, demographic characteristics, pleural effusion, underlying cause of the pleural effusion, the characteristics of the pleural fluid, and development of complications (if any) during the procedure were collected from the patient file, and recorded in the pre-prepared data collection form.

\section{Results}

In 255 patients, including 54 in the emergency medicine clinic, Pleuracan catheters were inserted in the hospital within one year for treatment purposes. Of these, 54 patients, 28 (51\%) were female, and 26 (48\%) were male. The mean age of males was 71.6 years.

The patients had respiratory distress ( $n=44: 81 \%)$, cough $(n=6: 11 \%)$, pain $(n=3: 5 \%)$, and dyspeptic complaints $(n=1: 1 \%)$. 
When the vital signs of the patients were examined, all were tachypneic (100\%). The pulse rate of 4 patients was within normal limits, but 50 patients were tachycardic (92\%). Nine patients (16\%) had hyperthermia. Two other patients (3\%) were hypothermic. The body temperatures of the remaining cases (80\%) were within normal limits. Besides this, 10 (18\%) patients were hypotensive, 24 (44\%) hypertensive, and 20 patients ( $37 \%$ ) were normotensive.

When the patient files were examined, 53 patients (98\%) had a history of at least one and 34 patients (62\%) had a history of more than one systemic disease. Similarly, 53 patients (98\%) were using at least one systemic drug. In half of the patients (50\%), effusion developed at least once in the past. In 20 patients (74\%), effusion was evacuated at least once.

The underlying etiologic factors were heart failure in 26 (48\%), malignancy in 20 (37\%), pneumonia in $4(7 \%)$, liver cirrhosis in $3(5 \%)$, and mesothelioma in $1(1 \%)$ patient. Breast cancer was the cause of malignancy in $13(65 \%)$ patients who developed pleural effusion due to malignancy. All of these patients were women. In four patients, the etiologic factor (20\%) was lung cancer. All of these patients were male. Other types of cancer were detected in 3 (15\%) patients.

All patients had computed tomograms of the thorax that were reported as massive effusion by the radiologist.

In the emergency medicine clinic of our hospital, one patient underwent bilateral Pleuracan, and 53 (98\%) patients unilateral Pleuracan insertions. Pneumothorax developed in four patients (7\%) who underwent Pleuracan catheter insertion. In one of these patients, bilateral pneumorax developed. No other complication was seen during follow-up period. An average of $644 \mathrm{ml}$ fluid was evacuated until the Pleuracan catheter was withdrawn. One (1.8\%) patient died during follow-up. Three patients (5.5\%) were discharged. Five patients (9.2) were referred to another center. Fortyfive patients (83\%) were hospitalized. One patient died of preexisting systemic diseases a few days after Pleuracan catheter was withdrawn.

The evacuated pleural fluid had exudative characteristics in $10(18 \%)$, and transudative characteristics in 44 (81\%) cases.

\section{Discussion}

In patients with pleural effusions, respiratory distress is the most common cause of emergency admissions [9-11]. In our series, $81 \%$ of the patients who underwent Pleuracan catheter insertion with the indication of pleural effusion applied with complaints of severe respiratory distress.

Heart failure is shown as the most frequently seen cause of pleural effusion ${ }^{[5-7]}$. This study seems to support the literature findings. In $48 \%$ of cases, the cause of effusion was heart failure. In all of the cases with pleural effusion due to heart failure, pleural fluid had transudative characteristics.

The second most common causes of pleural effusion are predominantly breast and lung cancers and metastatic cancers of the pleura ${ }^{[5-8]}$. We obtained similar results in patients who had Pleuracan catheter implanted in the emergency room of our hospital. In $37 \%$ of the cases, the cause of effusion was malignancy, and most of these patients had firstly breast and secondly lung cancer.

In our assessment, all patients were tachypneic, and 92\% of them were tachycardic. In their physical examination, respiratory sounds decreased in the area of effusion, and dullness was elicited at percussion. These findings are consistent with those in the literature $[2,3,5]$.

With systemic diseases such as heart failure and hypoalbuminemia, pleural fluid gradually disappears after control of the disease was achieved. However, after evacuating liquids accumulated due to malignancies, the fluid fills the pleural space again, and thus provides only short-term relief of the patient. Therefore, the decision to evacuate this fluid should be taken with a multidisciplinary approach. In fact, in all of our study population, the decision to empty the pleural fluid was given after shared evaluation made together with emergency medicine, internal medicine, radiology, and thoracic surgery specialists.

In the literature, pneumothorax was known to develop in $5 \%$ of the patients in whom pleural fluid was emptied $[12$, $15,16]$. In our study, pneumothorax developed in four patients (7\%). No further complication was observed in the follow-up of our patients.

Another point to be considered when draining the liquid is that the liquid should not be emptied more than 1000 $1500 \mathrm{cc}$ at a time. It has been reported that excess drainage may cause pulmonary edema and severe respiratory distress ${ }^{[15]}$. In our cases, $644 \mathrm{ml}$ of fluid was emptied. No patient developed severe hypotension or additional respiratory distress. One patient died a few days after removal of Pleuracan catheter due to complications secondary to systemic diseases.

\section{Conclusion}

When records of a series of 54 cases with massive pleural effusions whose pleural fluids were decided to be evacuated in emergency medicine clinic of SBUHNEAH within a one-year period were examined, etiological causes of massive pleural effusion, clinical and demographic character- 
istics of the patients, the procedures applied, and complications of the procedures were found to be in accordance with literature findings.

Peer-review: Externally peer-reviewed.

Authorship Contributions: Concept: N.K.; Design: N.K.; Data Collection or Processing: N.K., A.I.; Analysis or Interpretation: N.K., A.I.; Literature Search: N.K., A.I.; Writing: N.K.

Conflict of Interest: None declared.

Financial Disclosure: The authors declared that this study received no financial support.

\section{References}

1. Ünlü $M$, Şahin Ü, Akkaya A, Doğan A. Plevral efüzyonların etiyolojisinin araştırılması. Solunum Hastalıkları 2001;12:212-5.

2. Misserocchi G. Physiology and pathophysiology of pleural fluid turnover. Eur Respir J 1997;10:219-25. [CrossRef]

3. Bouros D, Hamm H. Infectious pleural effusion. Eur Respir Mon 2002;22:204-18.

4. Light RW. Clinical practice. Pleural effusion. N Engl J Med 2002;346:1971-7. [CrossRef]

5. Marel M. Epidemiology of pleural effusions. Eur Respir Mon 2002;22:146-56.

6. Light RW. Diagnostic principles in pleural disease. Eur Respir J 1997;10:476-81. [CrossRef]

7. Light RW. Diagnostic approach in a patient with pleural effu- sion. Eur Respir Mon 2002;22:131-6.

8. Kinasewitz GT. Transudative effusions. Eur Respir J 1997;10:714-8.

9. Guttikonda SNR, Vadapalli K. Approach to undifferentiated dyspnea in emergency department: aids in rapid clinical decision-making. Int J Emerg Med 2018;11:21. [CrossRef]

10. Tokur ME, Demiröz M, Girisgin AS, Ergin M. Approach to Pleural Effusions in the Emergency Department. JAEM 2013;12:155-63.

11. McGrath EE, Anderson PB. Diagnosis of pleural effusion: A systematic approach. Am J Crit Care 2011;20:119-27. [CrossRef]

12. Kohan JM, Poe RH, Israel RH, Kennedy JD, Benazzi RB, Kallay $\mathrm{MC}$, et al. Value of chest ultrasonography versus decubitus roentgenography for thoracentesis. Am Rev Respir Dis 1986;133;1124-6.

13. Bartter T, Santarelli R, Akers SM, Pratter MR. The evalution of pleural effusion. Chest 1994;106:1209-14. [CrossRef]

14. Villanueva AG, Gray AW Jr, Shahian DM, Williamson WA, Beamis JF Jr. Efficacy of short term versus long term tube thoracostomy drainage before tetracycline pleurodesis in the treatment of malignant pleural effusions. Thorax 1994;49:23-5. [CrossRef]

15. Collins TR, Sahn SA. Thoracocenthesis. Clinical value, complications, technical problems and patient's experience. Chest 1987;91:817-22. [CrossRef]

16. Bartter T, Mayo PD, Pratter MR, Santarelli RJ, Leeds WM, Akers SM. Minimally invasive techniques lower risk and higher yield for thoracentesis when performed by experienced operators. Chest 1993;103:1873-6. [CrossRef] 